\title{
El caso del reajuste salarial en el sector público chileno (2010). Una aproximación desde el análisis de discurso
}

\author{
Ma. Francisca Quiroga
}

Académica Instituto de Asuntos Públicos, Universidad de Chile E-mail: fquiroga@iap.uchile.cl

\section{Néstor Guerrero S.}

Docente Escuela de Gobierno y Gestión Pública, Universidad de Chile

E-mail: nestorguerrero@u.uchile.cl

\section{Sofia Schuster U.}

Docente Escuela de Gobierno y Gestión Pública, Universidad de Chile.

E-mail: sofiaschuster@u.uchile.cl

Resumen: ${ }^{1}$ El año 2010, por primera vez en la democracia post-autoritaria chilena, asume un gobierno de centro-derecha, y uno de los momentos clave para comprender sus lógicas políticas fue la visibilización mediática de las negociaciones de reajuste salarial para los trabajadores públicos. Teniendo como marco analítico categorías provenientes de la teoría del conflicto y, específicamente, del Análisis Crítico del Discurso (ACD), conjugado con aportes de la teoría de los actos de habla y la pragmática del discurso, el artículo expone dicho caso, evaluando los discursos y estrategias argumentativas. Se trata de un conflicto político institucionalizado en el que los actores políticos (gremiales, gubernamentales y parlamentarios) recurren a prácticas y discursos públicos que configuran un escenario sociopolítico que interesa examinar. Para ello, se interpretó la prensa escrita que dio cuenta del proceso durante noviembre y diciembre de 2010, analizando los discursos predominantes y la conformación de posicionamientos ideológicos en la triada Estado-Sociedad-Mercado.

Palabras clave: Condiciones laborales, salarios y beneficios, Sindicatos, Poder Ejecutivo, Poder Legislativo y proceso legislativo, Administración Pública.

\section{The case of wage adjustment in the chilean public sector (2010). An approach from the discourse analysis}

Abstract: In 2010, for the first time in Chilean post-authoritarian democracy, a centre-right government assumes power, and one of the key moments to comprehend its political logics and the interaction with the opposition was the mediatic visibility of salary increase negotiations for public workers. Based on an analytical framework with categories coming from conflict theory and, specifically, 
from Critical Discourse Analysis (CDA), paired with contributions from the speech act theory and the pragmatism of discourse, the article presents the case abovesaid, evaluating discourses and argumentative strategies. Being it an institutionalized political conflict where political actors (unions, government and parliamentary) have resorted to practices and public discourses that shape a socio-political scenario, it is interesting to examine it. For this purpose, the press that informed about this process during November and December 2010 was interpreted, analyzing dominant discourses and ideological formation in the triad State-Society-Market.

Key words: Labor conditions, salaries and benefits, Unions, Executive Power, Legislature and legislative process, Public Administration.

\section{O caso do reajuste salarial no setor público chileno (2010). Uma abordagem a partir da análise do discurso}

Resumo: Em 2010, pela primeira vez na democracia pós-autoritária chilena, assume um governo de centro-direita, e um dos momentos chave para entender suas lógicas políticas foi a visibilidade mediática das negociações de salário para os trabalhadores do governo. Tomando como marco analítico as categorias da teoria do conflito e, especificamente, a da Análise Crítica do Discurso (ACD), combinado com aporte provenientes da teoria dos atos de fala e a pragmática do discurso, o artigo expõe dito caso, avaliando discursos e estratégias argumentativas. Trata-se de um conflito político institucionalizado no qual os atores políticos (sindicatos, governo e parlamentares) utilizam práticas e discursos públicos que configuram um cenário sociopolítico interessante para ser examinado. Para isso, interpretou-se a impressa escrita que relatou esse processo durante os meses de novembro e dezembro de 2010, analisando os discursos dominantes e a criação de posições ideológicas na tríade Estado-Sociedade-Mercado.

Palavras-chave: condições de trabalho, salários e benefícios, sindicatos, Poder Executivo, Poder Legislativo e processo legislativo, Administração Pública.

$* * *$

\section{El reajuste salarial del sector público chileno en el marco de la democracia post-autoritaria (1990-2010): antecedentes y análisis de un conflicto institucionalizado}

El año 2010, tras 20 años de gobierno de la coalición de centroizquierda “Concertación de Partidos por la Democracia”, asume la presidencia de Chile el gobierno de Sebastián Piñera, liderando a la "Coalición por el Cambio" de centro-derecha ${ }^{2}$. Este giro en el ejercicio del poder político traería consigo variaciones en la priorización de los temas de la agenda de política pública (Sabatier 2007) las que reflejarían cuadrados ideológicos respecto al modo de gestionar el Estado y cómo enfrentar los imperativos neoliberales (Teichman 2009). Ello, más aún cuando el poder ejecutivo del período inmediatamente anterior estuvo liderado por Michelle Bachelet, la segunda Presidencia ejercida por un socialista desde 1990.

Sin embargo, es un hecho que la transición desde el autoritarismo a la democracia y el proceso mismo de "consolidación democrática", han 
estado adscritos a un modo de gestión política que exalta el valor del consenso, priorizando el establecimiento de acuerdos entre las elites dirigentes e inhibiendo los conflictos sociales y políticos. A esta fórmula contribuyen los diseños institucionales vigentes y las prácticas que mantienen las elites (Garretón 1991; Godoy 1999; Garcés 2004; Camargo 2008; Siavelis 2009).

Esta lógica de hacer política en Chile se ha expresado en diferentes escenarios donde interactúan actores institucionales y sociales. Uno de ellos es el proceso de reajuste salarial para el sector público chileno, un conflicto institucionalizado que conserva ciertas dinámicas predecibles de los actores, haciendo reconocibles sus prácticas y discursos en la arena pública. En efecto, el reajuste salarial para el sector público se torna visible para la opinión pública los últimos meses de cada año (noviembre y diciembre), pues los medios de comunicación otorgan amplia cobertura a sus actores principales: representantes del gobierno, de los trabajadores organizados y del parlamento, quienes se vinculan a esta coyuntura rutinaria buscando el logro de sus objetivos.

De allí que se utilice el concepto "conflicto institucionalizado” para dar cuenta de un proceso que, de acuerdo a la evidencia recogida, se activa comunicacionalmente a fines de cada año, reflejando que las prácticas y discursos de los actores se rutinizan, adquiriendo valor y estabilidad en el tiempo desde el momento en que se produce la redemocratización del país, en 1990. Desde entonces hasta marzo de 2010 fue la "Concertación" la coalición política encargada de definir las estrategias políticas para abordar el conflicto y la negociación entre funcionarios públicos y gobierno. No obstante, como se señaló, la elite política ha procesado las demandas y gestionado el aparato público de un modo pactado, evitando la movilización social, inhibiendo la participación ciudadana y priorizando el establecimiento de consensos políticos. A dicha práctica contribuye que la decisión del reajuste salarial para el sector público deba expresarse en leyes, adquiriendo relevancia el Congreso en el proceso de toma de decisión.

Con estos antecedentes, resulta interesante observar cuál ha sido la trayectoria política del conflicto del reajuste salarial en el período democrático. Finalizado el régimen autoritario en Chile, las bases programáticas de los gobiernos de la Concertación incluyeron una revalorización de la función pública en el marco del fortalecimiento de la institucionalidad estatal. A partir de ello, los trabajadores de la Administración Pública, organizados en asociaciones y gremios de funcionarios, han participado en procesos anuales de negociación colectiva con el Poder Ejecutivo, específicamente con el Ministerio de Hacienda, para mejorar sus condiciones laborales, siendo un eje clave de las demandas el aumento de las remuneraciones conforme el incremento del costo de vida y el crecimiento económico (adquiriendo relevancia "la cifra", generalmente expresada en un porcentaje). Adicionalmente, otras demandas contingentes a los momentos políticos son incluidas en los petitorios, destacando -por su reiteración a través de los años- los bonos, la calidad del empleo público, la estabilidad, la carrera funcionaria, los planes de retiro, entre otros. 
Estos procesos de negociación adquieren relevancia pública por cuanto se involucran en ellos actores políticos y sociales que, generalmente a través de los medios de comunicación, instalan discursos públicos en búsqueda de las adhesiones necesarias para el cumplimiento de sus objetivos. Ciertamente estos procesos anuales pueden ser categorizados como negociaciones, toda vez que se identifican intereses en pugna y objetivos divergentes.

Las demandas se articulan en torno a un discurso que apela al "trabajo decente”, concepto que se ha ido legitimando en el concierto mundial de la mano de la Organización Internacional del Trabajo (OIT), que desde hace más de una década reconoce la necesidad de contar con "un trabajo decente y productivo en condiciones de libertad, equidad, seguridad y dignidad humana” (OIT 1999:4), donde convergen cuatro objetivos estratégicos: la promoción de los derechos fundamentales en el trabajo; el empleo; la protección y seguridad social y el diálogo social. Particularmente, los trabajadores del sector público apuntan a proteger su poder adquisitivo, para lo cual sería necesario un reajuste real de las remuneraciones, respaldado por los índices macroeconómicos.

Durante este proceso se desarrolla un extenso diálogo entre los dirigentes y representantes de los trabajadores con las autoridades del gobierno, constituyéndose una interesante dinámica de interacción argumentativa. En un primer momento, los funcionarios presentan el porcentaje de reajuste que estiman pertinente considerando variables como la tasa de desempleo, la inflación y las expectativas de crecimiento nacional. Luego, el gobierno presenta una contraoferta que concuerda tanto con variables macroeconómicas como con la viabilidad presupuestaria respondiendo a una "política fiscal responsable" como criterio para argumentar en el debate público. Esta interacción da inicio a una fase de conflicto y negociación extra-legislativa, formalizada en una mesa de negociación del sector público con actores institucionales claramente identificados: la Central Unitaria de Trabajadores (CUT), la Agrupación Nacional de Empleados Fiscales (ANEF), los gremios sectoriales, el Ministerio de Hacienda y la Dirección de Presupuesto (DIPRES).

Así, el proceso global de reajuste salarial del sector público consta de dos etapas. La primera, extra-legislativa (concretada en la "Mesa del Sector Público”), en que se establece la negociación con los actores involucrados para acordar montos y, si procede, discutir temas laborales en el marco de las negociaciones con los gremios y representantes de los funcionarios públicos, asumiendo un rol clave el equipo de la DIPRES como representante del Ejecutivo para establecer propuestas acordes con las políticas de los gobiernos en ejercicio. Es una "negociación dura” que se mueve en base a las posiciones de los actores y a la lógica del "tira y afloja" centrándose el ejercicio de la negociación en un "regateo entre las partes”. En esta fase, los procedimientos no están escritos y adquieren valor las prácticas estables de los actores que participan; asimismo, los discursos están preconfigurados y son predecibles, surgiendo -eventualmente- como materialización de la negociación un protocolo de acuerdo. 
Una segunda fase, propiamente legislativa, consiste en que el Ejecutivo envía el Mensaje Presidencial al Congreso, constituyéndose éste en el espacio de formalización del acuerdo que, idealmente, debería representar los intereses y plasmar los objetivos de los participantes del proceso de negociación. No obstante, al tratarse de una negociación antecedida y condicionada por un conflicto sociopolítico, existen discursos predominantes que se tornan hegemónicos en la interacción argumentativa, actores con poder asimétrico y agendas políticas disímiles que no necesariamente se ajustan a la lógica de una "negociación efectiva".

\section{A propósito del reajuste salarial: I os discursos de los cuatro gobiernos de la concertación}

Al estudiar cómo se ha expresado esta dinámica en los cuatro gobiernos de la Concertación entre 1990 y 2009, se observa que cada uno de ellos le imprimió (deliberada o inercialmente) un sello propio. Este sello se expresó en discursos predominantes sobre el rol del Estado y la concepción de lo público, dando cuenta de un modo específico de abordar los conflictos.

El primer gobierno, presidido por Patricio Aylwin (1990-1993) se focalizó en el fortalecimiento de la institucionalidad democrática, debilitada por el régimen autoritario, activando una estrategia de revalorización de los servicios públicos. El correlato de esta estrategia se materializó en un reajuste salarial de $25 \%$ en el primer año de gobierno, cuando el Ministro de Hacienda era Alejandro Foxley (militante DC). Sin embargo, una crisis económica externa incidió en el proceso y en los efectos reales de este porcentaje, pues la variación anual de la inflación en ese período alcanzaba el $21,8 \%$. Durante este período el proyecto de reajuste ingresó al Congreso de forma sistemática con acuerdo entre trabajadores y autoridades. Este hecho puede explicarse por la dinámica política de la etapa transicional, donde se valoran los grandes acuerdos que hicieran viable la instalación de la democracia. En ese sentido, los pactos sociales constituían una condición necesaria para la gobernabilidad democrática y, vis a vis, la manifestación social era un recurso, en la práctica, inhibido desde las elites (Garcés 2004).

El segundo gobierno democrático (1994-2000), liderado por el Presidente Eduardo Frei Ruiz-Tagle (militante DC) inició el proceso de modernización de la gestión pública, instalándose con fuerza el paradigma de la "Nueva Gerencia Pública”, que recurría a un discurso configurado por conceptos tales como planificación estratégica, evaluación de resultados e incentivos a la productividad, cuya manifestación concreta radicó en los "Programas de Mejoramiento de la Gestión” (PMG). La lógica consistía en incorporar un monto variable a la remuneración de los funcionarios que se asociaba al cumplimiento de metas institucionales o los llamados "Convenios de Desempeño Colectivo”, incrementando de esta forma la renta de los trabajadores. Estas medidas se implementaron como una estrategia para 
elevar la calidad de la atención a los usuarios de la Administración Pública por medio de incentivos económicos al cumplir determinadas metas (Olavarría 2010).

En relación al proceso del reajuste salarial, en este período la cifra máxima se alcanzó en el primer año de gobierno, 1994, con un 12,2\%. Luego, cada año implicó un descenso, hasta llegar el 2000 con un porcentaje de reajuste del 4,3\%. Lo significativo, sin embargo, radica en que en los años 1997 y 1998 no hubo acuerdo pre-legislativo entre los gremios del sector público y el gobierno, cuyo Ministro de Hacienda era Eduardo Aninat (militante DC), lo que podría explicarse por la crisis económica internacional que afectó al país en esos años (la denominada “crisis asiática”).

En el caso del gobierno de Ricardo Lagos (militante PS-PPD), entre los años 2000 y 2006, el foco principal fue profundizar el proceso de modernización de la gestión pública, con un matiz: ampliar la mirada hacia reformas políticas del Estado. Se incorporaba entonces la noción de mejorar el Estado y repensar el proceso de modernización. Un aspecto distintivo es la generación de un acuerdo político entre gobierno y oposición (Acuerdo Lagos-Longueira, 2003) como reacción a los casos de sobresueldos que evidenciaba que el proceso de modernización del Estado centrado en la gestión no había asumido como foco las transformaciones de la sociedad y, por consiguiente, del Estado chileno. En este contexto, se instalan en la agenda decisional los tópicos de transparencia, concursabilidad de los cargos y remuneraciones de los altos directivos públicos, creándose el Servicio Civil y el Sistema de Alta Dirección Pública, entre otras medidas que formaron parte de una agenda de reformas político-legislativas.

En la relación con las asociaciones y gremios del sector público, existieron tensiones y se mantuvieron las lógicas de negociación de los gobiernos anteriores. El mayor reajuste del período Lagos fue de un $5 \%$ el año 2005, negociación que fue valorada positivamente por los involucrados en los discursos públicos de la época, destacándose la labor del Ministro de Hacienda Nicolás Eyzaguirre (militante PPD).

Finalmente, el cuarto gobierno concertacionista, el segundo socialista desde la redemocratización y el primero liderado por una mujer en Chile, Michelle Bachelet (2006-2010), comenzaba su período presidencial con un alto nivel de expectativas respecto a cómo se gestionaría el conflicto y la negociación. Sin duda, el contexto de crisis económica internacional del año 2008 complejizaba la situación nacional. Ese año el Ministro de Hacienda, Andrés Velasco (Independiente pro Concertación), estableció la misma modalidad de trabajo de los años anteriores, siendo significativo que se acordará un 10\% de reajuste apelando a la existencia de "factores macroeconómicos favorables”. En la ocasión los dirigentes de los trabajadores plantean públicamente que el proceso de negociación se centra en la cifra y que hay temas pendientes, tales como la equidad de género (a propósito de la oportunidad abierta por el discurso de Michelle Bachelet), la entrega de bonos y la calidad del empleo. 
Una mirada global al ciclo de los gobiernos de la Concertación da cuenta de una lógica similar para abordar el proceso de reajuste salarial del sector público, matizado por las contingencias políticas y económicas de cada período. En términos numéricos, se aprecia un progresivo descenso en los porcentajes de reajuste desde 1991, salvo por los años 2009 y 2010, que quiebran esta tendencia. El siguiente cuadro muestra las variaciones del porcentaje de reajuste para el sector público entre 1991 y 2010, así como el logro de acuerdos previos a la etapa legislativa en la mesa de negociación.

\section{Cuadro 1:}

Variaciones \% y existencia de acuerdos pre-legislativos Reajuste salarial del Sector Público 1991-2010

\begin{tabular}{|c|c|c|c|c|c|}
\hline Año & Reajuste & $\begin{array}{c}\text { Acuerdo/ } \\
\text { Desacuerdo }\end{array}$ & Año & Reajuste & $\begin{array}{c}\text { Acuerdo/ } \\
\text { Desacuerdo }\end{array}$ \\
\hline 1990 & $25,0 \%$ & Acuerdo & 2001 & $4,5 \%$ & Acuerdo \\
\hline 1991 & $18,0 \%$ & Acuerdo & 2002 & $3,0 \%$ & Sin Acuerdo \\
\hline 1992 & $14,0 \%$ & Acuerdo & 2003 & $2,7 \%$ & Sin Acuerdo \\
\hline 1993 & $15,0 \%$ & Acuerdo & 2004 & $3,5 \%$ & Acuerdo \\
\hline 1994 & $12,2 \%$ & Acuerdo & 2005 & $5,0 \%$ & Acuerdo \\
\hline 1995 & $11,0 \%$ & Acuerdo & 2006 & $5,2 \%$ & Acuerdo \\
\hline 1996 & $9,9 \%$ & Acuerdo & 2007 & $6,9 \%$ & Acuerdo \\
\hline 1997 & $6,0 \%$ & Sin Acuerdo & 2008 & $10,0 \%$ & Acuerdo \\
\hline 1998 & $5,0 \%$ & Sin Acuerdo & 2009 & $4,5 \%$ & Acuerdo \\
\hline 1999 & $4,9 \%$ & Acuerdo & 2010 & $4,2 \%$ & Sin Acuerdo \\
\hline 2000 & $4,3 \%$ & Acuerdo & \multicolumn{3}{|l}{} \\
\hline
\end{tabular}

Fuente: Elaboración propia sobre base ICAL, 2011

Se ve cómo durante el ciclo 1990-2010 en cinco oportunidades no se logró el acuerdo pre-legislativo, años que coinciden, en su mayoría, con recesos en la economía global. La revisión efectuada da cuenta de una lógica para gestionar el conflicto y el proceso de negociación que es similar en el período 1990-2010. Sin embargo, a pesar de la naturaleza “institucionalizada” y "rutinaria” del proceso, el año 2010 adquiere relevancia por las circunstancias que lo condicionan: los actores han modificado sus roles institucionales y existen varios elementos del contexto sociopolítico que contribuyen a complejizar el escenario del conflicto y la negociación política.

Es en este sentido que el año 2010 se torna relevante como foco de análisis del proceso de reajuste salarial para el sector público, toda vez que 
constituye un caso de estudio explicativo que permite establecer aproximaciones fundadas sobre el proceso político chileno, indagando en los discursos y prácticas de los actores desde una perspectiva analítica dual: por una parte, los actores se inscriben en un particular modo de hacer política en Chile (un modo rutinario); por otra, dado el cambio de gobierno, asumen por primera vez posiciones institucionales diferentes, afectando dichos discursos y prácticas (un modo crítico).

Además de esta introducción, el artículo tiene cinco secciones. Se propone un enfoque analítico-conceptual de los conflictos y la importancia del análisis de los discursos para su comprensión en el marco de los procesos políticos (parte II). Luego, se expone un breve apartado que da cuenta del anclaje analítico-metodológico, y de las técnicas y procedimientos utilizados (parte III). Con esa base, se realiza el análisis integrado del caso de estudio del reajuste salarial del año 2010, tomando como ejes analíticos la dinámica del conflicto y de los actores, así como la construcción de discursos públicos que prefiguran un escenario para la negociación y permiten la interpretación de lógicas predominantes de los actores políticos en el Chile post-autoritario (parte IV). Se culmina con algunas reflexiones finales (parte V).

\section{Conflictos políticos institucionalizados: la importancia del discurso público}

Una posibilidad cierta y recurrente en los procesos políticos es el surgimiento de conflictos entre actores con relaciones de poder asimétricas que pueden tener intereses u objetivos divergentes que se visibilizan a través de sus discursos y prácticas. En este contexto, los regímenes democráticos, tanto desde el enfoque procedimental como desde el deliberativo, han otorgado valor a la negociación. El primero, comprendiéndola como método democrático que facilita los “arreglos institucionales” entre sujetos racionales (Schumpeter 1952); el segundo, estableciéndola como un espacio donde los actores vuelcan su racionalidad comunicativa en un ejercicio dialógico a fin de conseguir el entendimiento intersubjetivo (Habermas 1999; Avritzer 2001). Desde este último enfoque, los discursos adquieren relevancia, toda vez que permiten visualizar los conflictos existentes en un sistema democrático, develando las ideologías cuando se presenta la comunicación sistemáticamente deformada.

Así, el conflicto es consustancial a las relaciones de poder y, por tanto, a la política. Siguiendo a Mouffe (2000) y Knoke (1990) "las relaciones sociales difícilmente son concebibles sin algún tipo de hegemonía provisional, sin exclusiones y desigualdades, sin antagonismos, debates y polémicas, sin conflictos y tensiones entre los agentes en cuestión” (Avimael 2011: 8). Por ello, más allá de la valoración que se le puede otorgar al conflicto en la vida social (Parsons1968; Simmel 2010; Dahrendorf 1966), su importancia como concepto para el análisis político radica en que refiere un en- 
frentamiento entre grupos a propósito de la disputa por un derecho o valores, teniendo como foco una reivindicación de justicia (Freund 1995).

Analíticamente, se pueden identificar en los conflictos ciertos elementos constitutivos comunes, tales como actores que poseen intereses disímiles, que ante determinados escenarios se plantean objetivos a alcanzar, adoptando para ello posiciones que pretenden hacer prevalecer mediante la movilización de sus recursos (Galtung 1973; Coppedge 1994).

Por otro lado, entre las diversas tipologías de conflicto existentes, se identifican aquellas que distinguen entre: i) reales ${ }^{3}$ e irreales $^{4}$ (Coser 1952); ii) latentes ${ }^{5}$ y manifiestos ${ }^{6}$ (Dahrendorf 1979); y iii) antagonismos ${ }^{7}$ y reivindicaciones $^{8}$ (Freund 1995). No obstante, este trabajo precisa de una categoría distinta, toda vez que las características propias del caso en estudio no son contenidas cabalmente en ninguna de las precedentes. Así, el reajuste salarial del sector público en Chile se trataría de un conflicto político institucionalizado, al considerar que las partes involucradas, además de hacer explícitas sus posiciones divergentes, mantienen estables sus posturas y comportamientos a través del tiempo, pasando a institucionalizarse. Según lo anterior, se está frente a un conflicto institucionalizado cuando la situación conflictiva se vuelve constante, es decir, los actores hacen explícitas sus posiciones divergentes en torno a un evento o situación específica permanentemente, tornándose habitual la tensión.

Desde la sociología política, un conflicto institucionalizado puede leerse como una “coyuntura política rutinaria” (Dobry 1988), que se caracteriza porque los actores dan muestras de un notable dominio de las crisis, rutinizando el fenómeno y circunscribiendo lo imprevisible. Bajo estas condiciones donde todo está controlado, los miembros de cualquier campo social no pueden actuar de otro modo que no sea aquel determinado por la lógica social de dicho campo o sector. Están, en cierto modo, cogidos en esta lógica.

Un efecto de esta adscripción a un modo específico de hacer las cosas, consiste en que los actores se sitúan en unas redes específicas o "telas de significación”, "producidas principalmente sin la intervención consciente y deliberada de los actores individuales (y menos aun de los actores colectivos) y que constituyen el marco y el alimento cognoscitivo ineludible de sus acciones, percepciones e interpretaciones" (Dobry 1988: 91). Es decir, los discursos y prácticas de los actores están insertos en visiones de mundo particulares, que constriñen su modo de operar sobre la realidad.

Por ello, el discurso "lejos de ser elemento transparente o neutro en el que (...) la política se pacifica, [es] más bien uno de esos lugares en que se ejercen, de manera privilegiada algunos de sus temibles poderes. Por más que en apariencia el discurso sea poca cosa, las prohibiciones que recaen sobre él revelan muy pronto su vinculación con el deseo y con el poder” (Foucault 1970: 15-16). De esta forma, Foucault critica la mirada 
“transparente y neutra” que Habermas (1999) tiene sobre los discursos que los actores realizan en la arena pública, complejizando aquella visión antropológica positiva donde el logro de acuerdos es el centro de la acción dialógica, insertando variables relacionadas con la búsqueda de poder de los actores y la existencia de agendas propias no exclusivamente racionales.

En una línea similar, van Dijk señala que el discurso es "un acontecimiento comunicativo que sucede en una situación social, presenta un escenario, tiene participantes que desempeñan distintos roles y determina acciones” (van Dijk 2005: 50). Es decir, los actores están insertos en un contexto que -de una u otra forma- determina sus discursos y prácticas. Específicamente, el discurso "puede comprenderse como un complejo conjunto de actos lingüísticos simultáneos secuencialmente interrelacionados, actos que se manifiestan a lo largo y ancho de los ámbitos sociales de acción como muestras semióticas (orales o escritas y temáticamente interrelacionadas) y muy frecuentemente como textos” (Wodak y Meyer 2003: 170).

Consecuentemente, si se comprende que el discurso "no es, simplemente, un conjunto de herramientas abstractas usadas para establecer o describir la realidad, sino que se usa esencialmente para transformar ciertos (...) acontecimientos en la sociedad” (Pardo 2007: 32), resulta pertinente utilizar el análisis de discurso como enfoque analítico ${ }^{9}$, pues posibilita identificar, entre otros elementos: i) los actos de habla de los actores, ii) la selección y uso estratégico del léxico, iii) los ejes de inclusión/exclusión; dimensiones que permiten configurar el "cuadrado ideológico" de los actores que participan en el conflicto. Por consiguiente, cuando se considera a los actores en el marco de la compleja dimensión intersubjetiva que los caracteriza, una entrada metodológica para comprender los conflictos políticos son sus discursos públicos. El análisis de discurso deviene entonces en un enfoque de análisis que permite ordenar las acciones públicas y comprender las prácticas de los actores involucrados, analizando su relación con las ideologías.

\section{Anclaje analítico-metodológico}

Esta investigación, de naturaleza cualitativa, es de carácter no experimental-transversal; es exploratoria, descriptiva y relacional, basada en un estudio de caso explicativo. La información seleccionada fue extraída de la revisión, registro y jerarquización de la prensa escrita que dio cuenta del proceso en 2010, considerando los siguientes medios: El Mostrador ${ }^{10}$, La Tercera $^{11}$ y El Mercurio ${ }^{12}$ De este proceso, se capturaron las declaraciones emitidas por los actores que se vincularon con mayor frecuencia al caso de estudio (mayor número de declaraciones). No se trata, sin embargo, de un análisis de medios $^{13}$, sino de un análisis de actores participantes seleccionados a partir de un criterio numérico de aparición en los medios. Por ello, se consideraron las secciones de los diarios que reflejan con mayor verosi- 
militud el discurso público de los actores (sin perjuicio de la edición consustancial de los medios), tales como la sección "País" y/o "Nacional”, descartando aquellas que exponen la posición del medio o de particulares sobre un tema, tales como "Editorial”, "Columnas de Opinión”, "Reportajes" y/o "Entrevistas". Consecuentemente, la selección de los tres medios de prensa obedeció a los siguientes criterios: i) se trata de medios de circulación nacional; ii) permiten obtener una frecuencia de aparición diaria; y iii) se encuentran disponibles en línea, lo que facilita su registro. El registro se realizó utilizando la siguiente tabla:

\section{Cuadro 2: \\ Tabla de registro y sistematización de información de prensa}

\begin{tabular}{|c|c|c|c|c|}
\hline Fecha & $\begin{array}{c}\text { Actor } \\
\text { emisor del } \\
\text { discurso }\end{array}$ & $\begin{array}{c}\text { Institución / } \\
\text { organización }\end{array}$ & $\begin{array}{c}\text { Idea central } \\
\text { noticia }\end{array}$ & $\begin{array}{c}\text { Declaración } \\
\text { emitida/discurso } \\
\text { público }\end{array}$ \\
\hline & & & & \\
\hline
\end{tabular}

Fuente: Elaboración propia.

Una vez aplicado el criterio de selección cuantitativo a los medios seleccionados, se ordenaron los discursos públicos en matrices de análisis que permiten interpretar la información, basándose en la estructura ideológica-argumentativa del discurso, que incluye las siguientes categorías: i) uso del lenguaje en contexto; ii) referentes del discurso, y iii) actos de habla predominantes. La codificación de estas matrices nos permite establecer la jerarquización de actores participantes y sus sectores de pertenencia.

\section{Cuadro 3: \\ Matriz con categorías de análisis}

\begin{tabular}{|c|c|c|}
\hline \multicolumn{3}{|c|}{ Estructura ideológica-argumentativa discurso } \\
\hline $\begin{array}{c}\text { Uso del lenguaje en } \\
\text { contexto (selección } \\
\text { temas y léxico) }\end{array}$ & $\begin{array}{c}\text { Referentes del } \\
\text { discurso }\end{array}$ & Actos de habla \\
\hline & & \\
\hline
\end{tabular}

Fuente: Elaboración propia.

De manera específica, las categorías de análisis de discurso utilizadas son:

i) Uso del lenguaje en contexto, que se refiere a la importancia que 
reviste el componente contextual pues "todo discurso es un objeto históricamente producido e interpretado, esto es, que se halla situado en el tiempo y espacio y que las estructuras de dominancia están legitimadas" (Wodak y Meyer 2003: 24).

ii) Los referentes del discurso, que según van Dijk corresponden a los actores públicos o institucionales que son incluidos en los discursos públicos (que pueden ser periodísticos o políticos), y que establecen una relación de poder y constituyen hegemonías discursivas.

iii) Los actos de habla, entendidas como las acciones lingüísticas que tienen efectos concretos sobre la realidad; su estudio se releva desde la pragmática del discurso y en términos sencillos es el "lenguaje en acción” (crítica, amenaza, interpelación, promesa). Mediante los actos de habla se pueden analizar discursos que, más que constatativos, devienen en lenguajes performativos respecto a determinados objetos, en el sentido que pueden reflejar un discurso ideológico que, bajo la pretensión de constatar o describir, "hace algo” a través de la selección de actos de habla (Austin 1962; Searle 1969). Es, en definitiva, el lenguaje performativo.

Luego se analizaron los discursos de los actores a partir de una estrategia de agrupamiento en niveles de análisis, estableciendo tres macrodimensiones:

i) Selección temas del discurso: los discursos presentan tópicos centrales que son seleccionados por los actores públicos para presentar sus posicionamientos ideológicos en las dinámicas de interacción, siendo interesante detectar aquellos temas que no se incluyen, los que se relacionan con un cierto contenido latente, con el tabú del objeto (Foucault 1970), correspondiendo a un "silencio objetivo”, a aquello que no se quiere decir explícitamente, los acuerdos tácitos para potenciar los discursos hegemónicos (Landowski 1993), haciendo reconocible la existencia de oposiciones, alianzas y coaliciones discursivas (Hajer 2005), de acuerdo a los temas que se incluyen en el discurso público.

ii) Selección y uso estratégico del léxico: se relaciona con aquellas trazas discursivas utilizadas, las que son priorizadas en desmedro de otras construcciones discursivas. Los discursos políticos suelen realzar y enfatizar ciertas categorías conceptuales, mientras omiten o desvirtúan otras. Desde la perspectiva de Wodak, esta noción puede reconocerse como topoi, es decir, aquellos argumentos estandarizados en el discurso público en la relación nosotros/ellos (Wodak 2000).

iii) Ejes de inclusión/exclusión: dicen relación con cómo los actores se visualizan a sí mismos y a los demás como parte o no de un determinado grupo, evidenciando niveles de pertenencia a un "nosotros” distinto y contrapuesto a un “ellos”. Dicha interpretación 
tiene como marco de análisis el “cuadrado ideológico”, es decir, una estructura polarizada mediante la cual se expresan ideologías políticas (van Dijk 2005). El “cuadrado ideológico” presenta las siguientes estrategias globales: i) Hacer énfasis en nuestras cosas buenas; ii) Hacer énfasis en sus cosas malas; iii) Minimizar nuestras cosas malas; iii) Minimizar sus cosas buenas (van Dijk, 2005: 30).

De tal modo, la relación contexto-actores-discurso es clave para el análisis, siguiendo los postulados de la escuela analítica-interpretativa del análisis crítico del discurso (Wodak 2000; Wodak y Meyer 2003; van Dijk 2005; Austin 1962; Searle 1969). Estas dimensiones operacionalizan las estrategias globales del "cuadrado ideológico" del discurso, constituyen el anclaje analítico-metodológico del trabajo y otorgan las condiciones teóricas para realizar el análisis aplicado del conflicto político institucionalizado: el caso del reajuste salarial en el sector público chileno.

\section{Análisis de discurso de un conflicto institucionalizado: el reajuste salarial del sector público chileno (2010)}

\section{El contexto}

Tras el triunfo electoral de la coalición de centro-derecha, la promesa de una "Nueva Forma de Gobernar" comenzó a generar expectativas sobre cómo el nuevo gobierno entendería y abordaría la función pública. Como primer gobierno de derecha desde el retorno a la democracia, se auto-presentaba positivamente y, a la vez, intentaba marcar una clara distancia con los gobiernos de la "Concertación", evidenciando la necesidad de consolidar una visión de un Estado eficiente y apelando a reforzar la mirada empresarial y la lógica del sector privado en la gestión pública.

En efecto, el diseño del primer gabinete ministerial, altamente "técnico" y "gerencial”, y la crítica velada a las “fallas del Estado” (como analogía a las fallas del mercado) durante el discurso del 21 de mayo de 2010, daban cuenta de esta nueva forma de entender la gestión del Estado. Asimismo, resulta fundamental considerar que al asumir una nueva coalición política se instala el tema de los despidos como eje clave de las posiciones de los actores en el debate público.

Esta situación produjo un clima de inseguridad para los funcionarios del sector público, que se evidenció en las nuevas demandas incorporadas a los petitorios. En efecto, la negociación de los gremios del sector público con un nuevo gobierno se hizo altamente compleja: por un lado, debido a la inexperiencia política de las nuevas autoridades que se desempeñaban por primera vez en el ejercicio del gobierno y, por otro, con un diseño institucional que habría otorgado un empoderamiento significativamente menor al Ministerio de Hacienda respecto a los gobiernos de la Concertación. Esta complejidad se exacerba por las denuncias de despidos masivos a los funcionarios públicos 
durante el 2010, las que son asumidas por la candidatura de Piñera como un hecho político relevante, acusando una “campaña del terror” en su contra.

La reacción política del candidato se materializó en dos acciones clave: la redacción y difusión pública de una carta dirigida a los funcionarios del sector público ${ }^{14}$ y el compromiso del candidato ante la Asociación Nacional de Empleados Fiscales (ANEF). Esta situación da cuenta de un conflicto latente que, eventualmente, formaría parte de la lógica del conflicto institucionalizado que se está analizando. El efecto inmediato de éste en medio del conflicto institucionalizado es la desconfianza de los gremios hacia las autoridades, condicionando el comportamiento de los actores.

En ese escenario, en julio de 2010 la ANEF entrega el "Pliego de Negociación Colectiva Sectorial 2010” al Ministro de Hacienda, Felipe Larraín, como respuesta a una reunión llevada a cabo con anterioridad. En ese documento se detallaba una lista de demandas y propuestas, destacando la petición de reincorporación de trabajadores/as despedidos “de forma arbitraria” afirmando que los empleados públicos son "trabajadores/as del Estado y no del gobierno de turno"15.

No obstante la solicitud gremial, desde marzo de 2010, según informó la prensa escrita, en el marco de la evaluación de programas de gobierno, comenzaron las desvinculaciones de funcionarios del sector público ${ }^{16}$. Esta percepción de inestabilidad laboral fue un elemento condicionante en el conflicto en torno al reajuste salarial 2010, cuya primera expresión pública concreta es la oferta oficial del gobierno, a comienzos de noviembre, de un porcentaje de reajuste correspondiente a un 3,7\%, una cifra que fue criticada por los dirigentes de los gremios, quienes llamaron inmediatamente a paralizar. Luego de las movilizaciones, se retoman las negociaciones. En noviembre el gobierno entrega una contrapropuesta correspondiente al 4,2\%, que no deja conforme a los trabajadores cuyo descontento se sumó, además, a la molestia generalizada a causa del tenso clima de despidos en el sector público.

Como se señaló, no hubo acuerdo pre-legislativo, por lo que el ejecutivo presenta a la Cámara de Diputados el Mensaje Presidencial con “discusión inmediata" ${ }^{17}$ que contemplaba un reajuste del 3,7\% inicialmente propuesto. Tras ser analizado por la Comisión de Hacienda, es rechazado. Luego pasa a la Cámara de Diputados con informe negativo de la comisión, prácticamente de forma inmediata se rechaza la idea de legislar sobre el proyecto poniendo en una compleja situación al Ministerio de Hacienda.

El Gobierno reingresa el proyecto de ley y el Senado habilita la iniciativa para su reingreso a la Cámara de Diputados. A mediados de diciembre, tras el reingreso del proyecto, la Cámara Baja aprueba, en primera instancia, únicamente los bonos y aguinaldos propuestos. Al día siguiente, el 16 de diciembre, la Cámara de Diputados aprueba, en definitiva, el reajuste del $4,2 \%$ por 44 votos a favor y 43 votos en contra. La aprobación fue posible únicamente luego que el Diputado Osvaldo Andrade (ex Ministro del Trabajo durante el gobierno de Bachelet), se ausentara de la sala de sesiones 
para evitar votar en relación al proyecto aludiendo a un acuerdo previo con la dirigencia de la CUT.

\section{Los actores}

En el caso en estudio, de acuerdo a la frecuencia de aparición, se han reconocido trece actores principales emitiendo declaraciones públicas en los medios de comunicación, tal como se muestra en el siguiente cuadro:

\section{Cuadro 4:}

Frecuencia de aparición de actores (Noviembre- Diciembre 2010) ${ }^{18}$

\begin{tabular}{|c|c|c|c|c|c|c|}
\hline \multirow{2}{*}{$\begin{array}{l}\text { Actor que emite el } \\
\text { discurso }\end{array}$} & \multirow{2}{*}{$\begin{array}{l}\text { Institución/ } \\
\text { organización }\end{array}$} & \multirow[b]{2}{*}{ Sector } & \multicolumn{4}{|c|}{ Frecuencia aparición } \\
\hline & & & "Mostfador & AIIERCERA & emol. & TOTAL \\
\hline Raúl de la Puente & ANEF & Gremios & 7 & 10 & 4 & 21 \\
\hline Felipe Larrain & MINHAC & Gobierno & 4 & 7 & 0 & 11 \\
\hline Arturo Martinez & CUT & Gremios & 3 & 3 & 2 & 8 \\
\hline Pablo Lorenzini & $\mathrm{DC}$ & C. de Diputados & 7 & 1 & 0 & 8 \\
\hline Osvaldo Andrade & PS & C. de Diputados & 3 & 2 & 1 & 6 \\
\hline Carlos Larrain & $\mathrm{RN}$ & $\mathrm{RN}$ & 3 & 1 & 1 & 5 \\
\hline Carolina Espinoza & CONFUSAM & Gremios & 2 & 1 & 2 & 5 \\
\hline Tucapel Jiménez & PPD & C. de Diputados & 4 & 0 & 0 & 4 \\
\hline Rodrigo Hinzpeter & $\begin{array}{l}\text { Ministerio } \\
\text { Interior }\end{array}$ & Gobierno & 0 & 1 & 3 & 4 \\
\hline Ena Von Baer & SEGEGOB & Gobierno & 1 & 1 & 2 & 4 \\
\hline Joaquín Godoy & $\mathrm{RN}$ & C. de Diputados & 2 & 1 & 1 & 4 \\
\hline Oscar Yáñez & ASEMUCH & Gremios & 0 & 2 & 1 & 3 \\
\hline $\begin{array}{l}\text { Alejandra } \\
\text { Sepúlveda }\end{array}$ & PRI & C. de Diputados & 1 & 2 & 0 & 3 \\
\hline
\end{tabular}

Fuente: Elaboración propia.

Dado los objetivos de este trabajo, se prescinde del análisis detallado de los agentes individuales, privilegiando su agrupación en tres campos o sectores de pertenencia: sector trabajadores organizados, sector parlamentario y sector gubernamental. El siguiente cuadro muestra esta agrupación:

\section{Cuadro 5: \\ Frecuencia de aparición consolidada por sectores (Noviembre- Diciembre 2010) ${ }^{19}$}

\begin{tabular}{|c|c|c|c|c|}
\hline \multirow{2}{*}{ Sector } & \multicolumn{4}{|c|}{ Frecuencia aparición } \\
\cline { 2 - 5 } & ${ }^{2}$ Mostrador & LATERCERA & emol. & TOTAL \\
\hline Trabajadores organizados del SP & $\mathbf{1 2}$ & $\mathbf{1 6}$ & $\mathbf{9}$ & $\mathbf{3 7}$ \\
\hline ANEF + CUT & 10 & 13 & 6 & 29 \\
\hline Gremios sectoriales & 2 & 3 & 3 & 8 \\
\hline Cámara de Diputados & $\mathbf{1 7}$ & $\mathbf{6}$ & $\mathbf{2}$ & $\mathbf{2 5}$ \\
\hline Coalición por el Cambio & 2 & 1 & 1 & 4 \\
\hline Concertación & 14 & 3 & 1 & 18 \\
\hline Independiente u otro & 1 & 2 & 0 & 3 \\
\hline Gobierno & $\mathbf{5}$ & $\mathbf{9}$ & $\mathbf{5}$ & $\mathbf{1 9}$ \\
\hline
\end{tabular}

Fuente: Elaboración propia. 
Se observa la alta importancia que alcanzan los trabajadores organizados del sector público (ANEF, CUT, CONFUSAM, ASEMUCH). En orden decreciente, aparece el sector parlamentario (un total de 25 apariciones) y el gobierno (con un total de 19 apariciones).

En este sentido, es relevante apuntar que de los 13 gremios participantes de la mesa de negociación sólo dos adquieren visibilidad pública (CONFUSAM y ASEMUCH), acompañando a las organizaciones protagonistas (CUT y ANEF) de acuerdo al alto número de apariciones públicas (78\%), que en el relato periodístico se centran en sus dirigentes (los que llevan más de 10 años en sus funciones).

Esta primera descripción de los actores involucrados, así como su sectorialización, nos permite realizar la apreciación política de su vinculación en el conflicto, para luego analizar sus discursos. El análisis se realiza por campos de acción o sectores de pertenencia, bajo los supuestos teóricos de que los campos o sectores tienen lógicas de acción propias, y que los actores se analizan no como individuos, sino que como principio de agrupación de discursos, es decir, como unidad y origen de sus “telas de significaciones” (Dobry 1988).

\section{Cuadro 6: \\ Apreciación política del conflicto: objetivos y posición por sectores involucrados}

\begin{tabular}{|c|c|c|}
\hline Sector & Objetivos & Posición \\
\hline Gobierno & $\begin{array}{l}\text { - Lograr un reajuste salarial para el Sector } \\
\text { Público con una cifra previamente definida. } \\
\text { - Instalar la importancia de las variables } \\
\text { macroeconómicas en el discurs o público como } \\
\text { marco de la discusión. } \\
\text { - Lograr votos necesarios en el Parlamento para } \\
\text { aprobar proyecto de ley enviado por el ejecutivo. }\end{array}$ & $\begin{array}{l}\text { - Ofrece un reajuste de salarios } \\
\text { de acuerdo a las variables } \\
\text { macro-económicas } \\
\text { responsables y prudentes } \\
\text { ( } 3,7 \% \text { como oferta inicial). }\end{array}$ \\
\hline $\begin{array}{l}\text { Parlamento } \\
\text { (Coalición por } \\
\text { el Cambio ) }\end{array}$ & $\begin{array}{l}\text { - Apoyar proyecto de ley enviado porel } \\
\text { Ejecutivo, apelando a la necesidad de incrementer } \\
\text { la cifra dentro del marco establecido por éste. } \\
\text { - Criticar el desempeño dela Concertación como } \\
\text { oposición en el Congreso, destacando rol } \\
\text { obstaculizador. }\end{array}$ & $\begin{array}{l}\text { - Apoya la oferta dereajuste } \\
\text { del gobierno, proponiendo una } \\
\text { cifra mayor dentro del marco } \\
\text { establecido porel gobierno. }\end{array}$ \\
\hline $\begin{array}{l}\text { Parlamento } \\
\text { (Concertación) }\end{array}$ & $\begin{array}{l}\text { - Mostrar sevinculados a demandas delos } \\
\text { trabajadores organizados (como parte de un } \\
\text { "nosotros"). } \\
\text { - Criticar al go bierno en el desempeño del } \\
\text { conflicto, evidenciando su falta de comprensión } \\
\text { de lo público y su experienciaen el mundo } \\
\text { empresarial. } \\
\text { - Instalar el tema de los despidos injustificados } \\
\text { dentro del sector público (objetivo implicito: } \\
\text { defender a los funcionarios públicos pro- } \\
\text { Concertación). }\end{array}$ & $\begin{array}{l}\text { - Rechazar la oferta realizada } \\
\text { por el gobierno en primera } \\
\text { instancia } \\
\text { - Apoyar la demanda realizada } \\
\text { por los trabajadores } \\
\text { organizados del Sector Público } \\
\text { ( } 8,9 \% \text { como demanda inicial). }\end{array}$ \\
\hline $\begin{array}{l}\text { Trabajadores } \\
\text { organizados } \\
\text { del Sector } \\
\text { Público }\end{array}$ & $\begin{array}{l}\text { - Criticar al gobierno por la ausencia del Ministro } \\
\text { de Haciendaen la mesa de negociación. } \\
\text { - Instalar el tópico de los despidos en el sector } \\
\text { público y vincularlo al princịio de la estabilidad } \\
\text { laboral. } \\
\text { - Reintegrar a los funcionerios despedidos en } \\
\text { forma arbitraria } \\
\text { - Conseguir un bono especial de retiro para } \\
\text { funcionarios con daño previsional. }\end{array}$ & $\begin{array}{l}\text { - Exigir un reajuste de salarios } \\
\text { de acuerdo a variables macro- } \\
\text { económicas favorables } \\
\text { ( } 8,9 \% \text { como demanda inicial) y } \\
\text { principios oriantadores } \\
\text { (estabilidad laboral, trabajo } \\
\text { digno). }\end{array}$ \\
\hline
\end{tabular}

Fuente: Elaboración propia. 
Del cuadro se evidencia, en primer lugar, que todos los sectores están de acuerdo con el modelo económico chileno: la importancia de las variables macro-económicas (que no son cuestionadas) se utilizan como argumentos centrales de la discusión pública, resaltando la dimensión económica por sobre la política. En términos de Wodak (2000), la hegemonía económica en el debate político deviene en el topoi de la política chilena, alzándose como aquel argumento estandarizado en el discurso público en la relación nosotros/ellos. De este modo, todos los actores del conflicto están inscritos en una misma lógica de entender la construcción de políticas públicas y el proceso político como una construcción que, normativamente, debe adscribirse a las condiciones de posibilidad que otorgue el crecimiento económico, la tasa de inflación, las finanzas públicas, la disciplina fiscal, el reajuste del sector privado, entre otras variables económicas.

En segundo lugar, se evidencia la conformación de posiciones divergentes, que se confrontan dentro del marco establecido: la cifra, y que pueden clasificarse en dos grandes bloques que configuran agrupaciones de discurso: trabajadores organizados más parlamentarios de la Concertación, por un lado, y gobierno más parlamentarios de la Coalición por el Cambio (RN y UDI), por otro. La primera alianza aparece en los medios más del doble de oportunidades que la segunda, tal como se muestra en el siguiente cuadro.

\section{Cuadro 7:}

Frecuencia de aparición de sectores / agrupaciones de discurso

\begin{tabular}{|c|c|c|c|c|}
\hline \multirow{2}{*}{ Sector } & \multicolumn{4}{|c|}{ Frecuencia aparición } \\
\cline { 2 - 5 } & "Mostradar & LATERCERA & emol. & TOTAL \\
\hline $\begin{array}{c}\text { Trabajadores organizados } \\
+\end{array}$ & 27 & 21 & 10 & 58 \\
\hline $\begin{array}{c}\text { Parlamentarios Concertación } \\
\begin{array}{c}\text { Gobierno } \\
+\end{array} \\
\text { Parlamentarios Coalición por el Cambio }\end{array}$ & 7 & 10 & 6 & 23 \\
\hline
\end{tabular}

Fuente: Elaboración propia.

La estructuración discursiva dentro del conflicto adquiere relevancia en el particular contexto socio-político del año 2010 (post-terremoto, rescate de los mineros, incendio de la cárcel de San Miguel), pues se configura como una oportunidad política para que la Concertación se articule como oposición, critique el desempeño del gobierno y destaque su mirada empresarial por sobre la conducción políticogubernamental. 


\section{Los discursos}

Se ha señalado que el análisis del discurso supone indagar en la ideología que subyace a todo discurso político. Siguiendo esta premisa, se analiza el "cuadrado ideológico" de los actores mediante las siguientes dimensiones: temas del discurso y ejes de inclusión/exclusión.

En lo relativo a la selección de temas del discurso, los parlamentarios, como campo o sector específico, apelan a la importancia del Congreso como arena de toma de decisión valorando los recursos políticos decisionales que al respecto tienen los congresistas ("Tal como lo dije este fin de semana en la ANEF, Señor Ministro corte el leseo y envíe el proyecto, somos los parlamentarios quienes votamos”, Diputado DC; "la última palabra la tiene el Gobierno y el Senado en los próximos días en que se va a discutir nuevamente el reajuste”, Diputado UDI). Sin embargo, existen importantes diferencias dependiendo si se trata de parlamentarios de gobierno o de oposición.

En la bancada de la Concertación, el primer tema es criticar y evaluar la acción del gobierno al despedir funcionarios públicos y respaldar las demandas de los funcionarios públicos ("El Gobierno está ofreciendo sólo un 3,7\% cifra que no está totalmente lejana a las expectativas de los empleados públicos, quienes han sufrido desde que asumió el presidente Piñera, despidos masivos por razones políticas”, Diputado PPD; "Llamo al Gobierno a terminar con el maltrato, a terminar con los despidos de los funcionarios públicos porque al parecer a este gobierno no le interesa ni la trayectoria ni la experiencia ni la dignidad ni el respeto a las personas”, Senadora PS; "La Concertación y el mundo independiente harán presente que este es el parlamento: No más despidos y reajuste para los trabajadores públicos de 5\%”, Diputado DC). A partir de estos discursos, se pueden identificar como temas centrales del discurso-posición de la Concertación: i) despidos de los funcionarios públicos y ii) el aumento de la cifra de reajuste salarial.

Por otro lado, en la bancada de diputados de la Coalición por el Cambio se aprecia el uso de conceptos nominales: "tarea de todos"; “el bien de Chile" para evaluar la propuesta del gobierno, siendo relevante el efecto de ambigüedad en los discursos sobre la cifra del 3,7\% de reajuste salarial que corresponde a la oferta del Gobierno ("El Gobierno ha hecho los mayores esfuerzos. Los Ministros de Hacienda tienen que defender las arcas fiscales pero siempre un Gobierno puede seguir haciendo esfuerzos”, Diputado UDI).

En lo que respecta a ejes de inclusión/exclusión, en la bancada de parlamentarios de la Concertación se aprecia la "otra presentación negativa" centrándose en la figura del Presidente "Piñera" ${ }^{20}$ con uso de aseveraciones y evaluaciones negativas sobre el ejercicio del gobierno ("El Gobierno tiene una incapacidad de dialogar, de llegar a acuerdos", Diputado DC; "Lamento que el Ejecutivo mantenga una postura inflexi- 
ble que no contribuye en nada al crecimiento equitativo que es la gran deuda que tiene este país con los trabajadores"; "apoyaremos todas las decisiones que tomen los dirigentes sindicales...”, Diputado PPD). Además se incorporan estrategias retóricas recurrentes como el uso de la exageración y adición de temas con fines persuasivos ("la cifra está totalmente lejana a las expectativas de los empleados públicos, quienes además han sufrido desde que asumió el Presidente Piñera despidos masivos por razones políticas”, Diputado PPD).

De esta forma se articula discursivamente un "nosotros" (la Concertación) que apoya a las demandas de los trabajadores y valida el rol de los dirigentes de los trabajadores ("...Apoyaremos todas las decisiones que tomen los dirigentes sindicales..., Diputado PPD), siendo el eje de distancia y constitutivo de un "otro distinto": el gobierno de Piñera.

En lo relativo a la Coalición por el Cambio, cabe señalar que los parlamentarios RN apelan a un pronombre inclusivo "nuestro gobierno" (“...nuestro Gobierno ha sido mucho más exigente con el sector público...”, Diputado RN), mientras los parlamentarios UDI hablan en tercera persona "el gobierno" (“...el Gobierno ha hecho los mayores esfuerzos”, Diputado UDI.), siendo el eje común de ambos destacar el "otro distinto": Concertación, con el uso de la "otra presentación negativa" (“¡Por Dios que les hace falta Velasco! A la Concertación se le acabó la ponderación...nos están negando la sal y el agua. Así no se construye país... responsabilidad con el manejos de las finanzas, eso es lo que ellos hicieron durante veinte años”, Diputado UDI; “La Concertación... impide que haya un reajuste para el sector público, anteponiendo los intereses político-partidistas"; "Esta actitud viene a demostrar una vez más que perdió el contacto y la empatía con la gente, y sólo tiene por objetivo tratar de infringir daño al gobierno”, Senador UDI).

En este sentido, es posible identificar un contenido latente que apela a esperar una cifra más alta -sin dejar de lado los principios de estabilidad y variables macroeconómicas para establecer los límites de la cifra propuesta- y a criticar negativamente a la Concertación apelando a los siguientes tópicos: i) rol obstaculizador en el Congreso ${ }^{21}$, ii) consecuencias negativas para el sector público por la no aprobación del reajuste propuesto, iii) criticar el rol de los “dirigentes sindicales" y su vinculación con las elites de la Concertación ("El objetivo de la Concertación y de la ANEF es provocar un daño político", Diputado UDI).

A continuación se presenta gráficamente la selección de temas del discurso parlamentario, destacando las coincidencias y ejes distintivos. 


\section{Cuadro 8: \\ Selección de temas y eje de inclusión/exclusión por Coalición Política dentro del Parlamento}

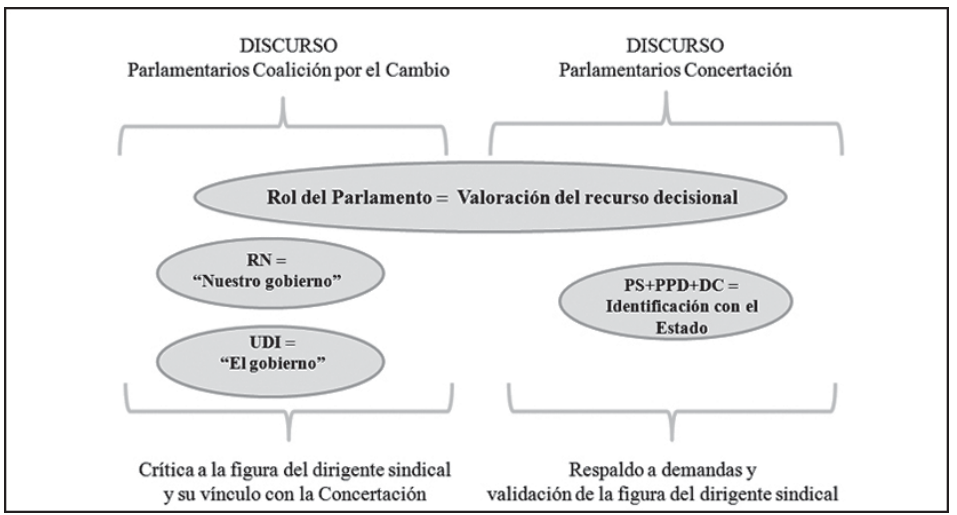

Fuente: Elaboración propia.

Ahora bien, en el sector ANEF y gremios del sector público se identifican temas del discurso ejes del debate público, tales como: "trabajo digno", "salario digno y real", "movilizaciones" ("Por el derecho al trabajo y un reajuste digno, tendremos una movilización mayor porque los funcionarios públicos estamos decididos a tener un trabajo digno como lo dice la OIT”, ANEF), pero hay una selección y orden de los temas distintivo para cada uno, demostrando la existencia de visiones diferentes y competencia de liderazgos entre las figuras públicas que son referentes del discurso público. Es relevante mencionar que en el discurso público de la ANEF, representada por Raúl de la Puente, el orden y nivel de recurrencia de los temas son los siguientes: criticar las respuestas y acciones del presidente Piñera y sus ministros, para lo cual utiliza ironías ("No nos parece que un hijo de un funcionario público, padre de un funcionario público, hermano de un funcionario público haya despedido este año a cinco mil funcionarios públicos”, ANEF), y frases nominales con poder identificatorio, tales como: "gobierno empresarial" ("Este es un gobierno empresarial, que aun no aprende a gobernar en democracia, porque no escucha, no dialoga, impone y despide”, ANEF) centrándose en evaluar sus acciones desde la lógica del "otro lejano y distante” que es el gobierno en ejercicio.

Los gremios sectoriales que se visibilizan en el conflicto (con menor nivel de aparición en los medios comparado con los demás trabajadores organizados del sector público; ver cuadro 4), al ser parte de la mesa de negociación, seleccionan dichos temas en sus discursos ("lo que los gremios quieren es que haya una firma de un protocolo de acuerdo con respecto a los criterios de los despidos..., cosa que el gobierno no está dispuesto a hacer”, CUT), centrándose en la agenda específica del petitorio (eje común con la ANEF): el aumento de la cifra del reajuste y la firma del protocolo de acuerdo con respecto a los criterios de despidos de los funcionarios públicos. 
En los ejes de inclusión/exclusión de temas podemos apreciar que el discurso público de la ANEF habla desde un "nosotros" apelando a la acción, focalizándose en el tema de los despidos y el reajuste digno. Asimismo realiza evaluaciones negativas de las formas de ejercer gobierno mencionando recurrentemente al Presidente Sebastián Piñera y a los Ministros. Es posible interpretar que el discurso público de la ANEF durante el conflicto está dirigido hacia los parlamentarios y la ciudadanía, constituyendo un discurso de tipo confrontacional-ideológico ("Los parlamentarios tienen la oportunidad de ver de qué manera también defienden a los trabajadores, para ellos va a ser una prueba y nosotros vamos a observar cuando ellos voten", ANEF; "Solicitamos a la ciudadanía que solidarice con los trabajadores y no asista a los servicios públicos”, ANEF).

Estrategia distinta es la efectuada por los gremios, que asumen un rol pragmático apelando a los temas de disenso en la mesa de negociación, articulando un tipo de discurso negociador-pragmático ("Nuestra intención es avanzar y en una negociación no siempre se gana todo. Pero en esta primera oferta el gobierno no ha ofrecido absolutamente nada”, CONFUSAM; "Creo que el proyecto se va a ir sin acuerdo... vamos a pensar... si podemos hacer alguna contraoferta, pero lo veo muy difícil”, CUT).

A continuación se presenta gráficamente el cuadrado ideológico con los temas y lógica distintiva de los discursos públicos de la ANEF y los gremios.

\section{Cuadro 9: \\ Selección de temas y eje de inclusión/exclusión en ANEF y gremios sectoriales.}

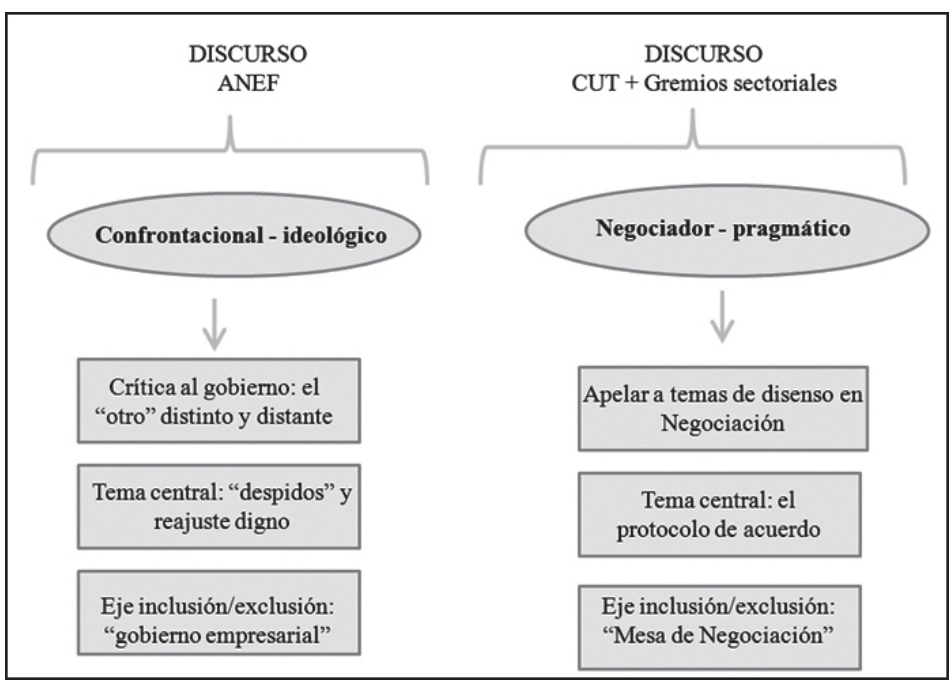

Fuente: Elaboración propia. 
Por otro lado, en el discurso del sector gobierno y parlamentarios de la Coalición por el Cambio (RN y UDI) hay un "nosotros” que apela a un "marco establecido" ("Tenemos que pensar en la realidad del mercado laboral y la pregunta es cómo uno llega y cómo uno construye los números y qué está pasando con el sector privado que justamente corresponde a una tasa inferior al 4\%", Ministro de Hacienda; "Probablemente la situación económica del país tenga límites, pero se puede hacer un esfuerzo mayor" Senador UDI; “El Gobierno va a estar dispuesto al diálogo, pero siempre respetando los marcos de la responsabilidad respecto al gasto del sector público, a la creación de empleo y a nuestra economía”. Ministra Vocera de Gobierno).

En dicho marco se inscribe discursivamente el sector gubernamental y el oficialismo, evidenciando un contenido latente que hace referencia a los principios y valores predominantes del modelo económico neoliberal imperante en Chile en los últimos 30 años, (Teichman 2009), lo que es plenamente coincidente con el cuadrado ideológico de centro-derecha, constituyéndose en los principios explícitos que orientan sus discursos políticos (validación por principios). En cambio, para la Concertación es un "no querer decir”, un silencio objetivo que tensiona a los miembros de la coalición política y genera divisiones internas en los discursos públicos; sin embargo, dichos "imperativos del neoliberalismo" (Teichman 2009), fueron validados por la Concertación en el ejercicio del gobierno, ajustando el modelo político y económico desde el pragmatismo (validación por acción).

A continuación, considerando el régimen de decibilidad del discurso público (“querer decir” y "no querer decir”) desde la socio-semiótica (Landowski 1993), se presenta el cuadrado ideológico de los sectores políticos identificados en el conflicto (centro- derecha: gobierno y parlamentarios de la Coalición por el Cambio; centro-izquierda: ANEF, CUT, gremios sectoriales y parlamentarios de la Concertación).

\section{Cuadro 10:}

Régimen de decibilidad discursos Centro-Derecha y Centro-Izquierda.

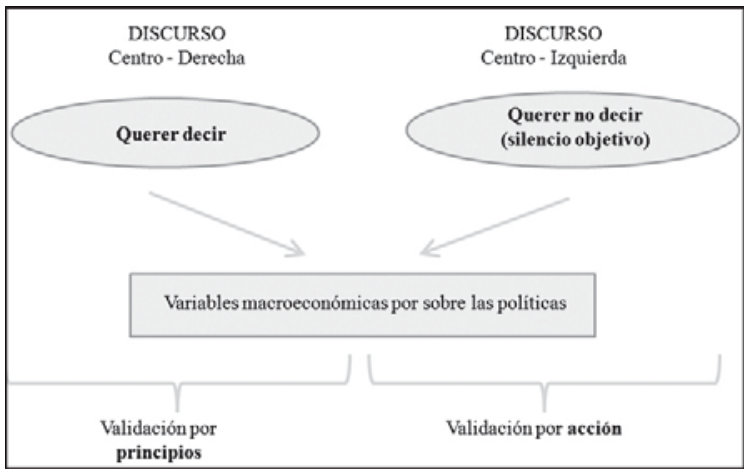

Fuente: Elaboración propia. 
Finalmente, el caso -en palabras de Freund- se trata de una reivindicación de los trabajadores y trabajadoras del sector público, el que además evidencia los cuadrados ideológicos de los actores políticos que intervienen en el conflicto. En este contexto, el centrarse en los discursos de los actores permite evidenciar las relaciones de poder existentes en un conflicto determinado, el que en este caso toma la forma de institucionalizado. De allí la importancia de esta aproximación analítica basadas en las categorías del Análisis Crítico del Discurso, que permite sistematizar y comprender un conflicto sin sobre-simplificarlo, incluyendo y valorando la dimensión subjetiva de los actores que participan en éste, permitiendo identificar la selección estratégica del léxico, la selección de los temas del discurso, y los ejes de inclusión/exclusión, los que conforman finalmente el cuadrado ideológico de los actores intervinientes en el conflicto.

\section{Reflexiones finales}

Luego del retorno de la democracia en Chile, en 1990, los trabajadores del sector público han establecido negociaciones anuales con los sucesivos gobiernos a fin de mejorar sus condiciones laborales. Estas negociaciones, que se expresan en la discusión pública como "la cifra de reajuste salarial", se inscriben en un escenario de conflicto, dado los intereses y posiciones divergentes de los actores políticos y gremiales que participan. Es un conflicto institucionalizado en el sentido que se activa públicamente al finalizar cada año de modo reiterado, adquiriendo valor las normas informales para los actores, articulándose tipos de discursos relativamente estables en la discusión política. El año 2010 se torna especialmente relevante como foco de investigación debido al cambio de gobierno: es primera vez que el conflicto y la negociación debe ser administrado por una coalición política de centro-derecha.

$\mathrm{Al}$ respecto, este artículo ha analizado detalladamente el proceso político de reajuste salarial para el sector público chileno del año 2010, problematizando acerca del contexto, los actores involucrados, las lógicas subyacentes a los campos de pertenencia de estos actores (Dobry 1998), así como sus discursos y estrategias de argumentación predominantes en la esfera pública y las hegemonías discursivas asociadas a las ideologías y sus manifestaciones en el "decir público". Lo anterior, ha sido posible gracias al análisis del conflicto desde la perspectiva analítica del Análisis Crítico del Discurso (Wodak 2000; Wodak y Meyer 2003; van Dijk 1997) y los aportes de la teoría de los actos de habla y la pragmática del discurso (Austin 1962; Searle 1969). En este sentido, el caso explicativo es analizado en un escenario sociopolítico en donde se movilizan ideologías y acciones a través de los medios de comunicación, estando insertos los actores en un contexto que determina sus discursos y prácticas (van Dijk 1997).

Una primera reflexión al finalizar, sugiere que la gestión gubernamental y parlamentaria de este conflicto no escapa al modo particular de hacer política en el Chile post-autoritario, caracterizado por la lógica imperativa de 
los consensos y el establecimiento de grandes acuerdos, reflejando un cierto temor al conflicto por parte de las elites (Camargo 2008) y a la inhibición de las expresiones sociales y populares en la esfera pública tras la redemocratización (Garcés 2004).

En segundo lugar, el estudio de los discursos sugiere la hegemonía que el discurso económico, en tanto “tela de significación” en el sentido de ser el marco ineludible de acciones, percepciones e interpretaciones (Dobry 1988), ha alcanzado en las argumentaciones públicas, puesto que los respaldos para sustentar posiciones y expresar intereses -tanto del gobierno, los gremios de trabajadores, los parlamentarios de oficialismo y oposiciónencuentran sus fundamentos en las variables macroeconómicas. En términos de Wodak (2003) identificamos el topoi: "variables macroeconómicas" como un argumento estandarizado de las elites decisionales para fundamentar las declaraciones públicas en el conflicto estudiado. Mientras la centro-derecha valida "el modelo" por los principios que orientan su ideología (reflejando un “querer decir”), la centro-izquierda lo valida por la acción que desarrolló en el ejercicio del gobierno (reflejando un "no querer decir”, un “tabú del objeto” o “silencio objetivo”).

Una tercera cuestión interesante es la dinámica interna que se visualiza entre los trabajadores organizados del sector público, al identificar dos estilos de entender el conflicto, reflejados en dos tipos de discursos públicos. Mientras la Asociación Nacional de Empleados Fiscales, ANEF, articula un discurso confrontacional-ideológico centrado en el conflicto y en la crítica al gobierno en ejercicio, los gremios sectoriales y la Central Unitaria de Trabajadores (en su rol moderador del proceso) configuran un tipo de discurso centrado en el proceso de la negociación enfatizando la necesidad de alcanzar acuerdos, que hemos denominado negociador-pragmático.

Finalmente, cabría reflexionar acerca de los modos de identificación con el Estado y con "lo público” que los discursos de las coaliciones políticas permiten evidenciar. Mientras los discursos de la Concertación denotan una alta identificación con el Estado (dado sus veinte años de ejercicio del gobierno) expresado en el uso del lenguaje para referirse a los “empleados fiscales” y "trabajadores del Estado”, validando a los dirigentes sindicales como actor sociopolítico; la Coalición por el Cambio (centro-derecha) formula un discurso que concibe a los trabajadores del sector público como “servidores”, criticando simultáneamente la figura del dirigente sindical. 


\section{Notas}

${ }^{1}$ Este artículo ha sido posible gracias a la invaluable contribución de la asistente de investigación Javiera Herrera, Licenciada en Ciencias Políticas y Gubernamentales, y egresada del Magíster en Ciencia Política de la Universidad de Chile, E-mail: javieraherreraa@gmail.com.

${ }^{2}$ La Concertación de Partidos por la Democracia está conformada por cuatro partidos eje: Partido Socialista -PS-, Partido Por la Democracia -PPD-, Partido Radical Socialdemócrata -PRSD- y Partido Demócrata Cristiano -PDC. La "Coalición por el Cambio”, en tanto, la conforman dos partidos eje: Renovación Nacional -RN- y la Unión Demócrata Independiente -UDI.

3 “...los conflictos reales surgen cuando los hombres chocan con ocasión del reclamo de derechos basados en la frustración de sus pretensiones y expectativas de ganancias” (Coser 1956:62).

${ }^{4}$ El irreal no busca satisfacer ninguna demanda en particular, sino liberar en parte la tensión, seleccionando un antagonista cualquiera, siendo un fin en sí mismo (Coser 1956).

${ }^{5}$ Aquellos donde las partes involucradas no manifiestan explícitamente sus posiciones en torno a un evento o situación específica (Dahrendorf 1979).

${ }^{6}$ Aquellos en que las partes involucradas hacen explícitas sus posiciones divergentes en torno a un evento o situación específica que desencadena el conflicto (Dahrendorf 1979).

7 “...los antagonismos no oponen hechos o realidades empíricamente comprobables, sino valores cuyo fundamento reside en apreciaciones y creencias...” (Freund 1995: 125).

“...se relacionan con bienes materiales o ideas o espacio o territorio (...) no hay límite para las reivindicaciones...” (Freund 1995: 124).

${ }^{9} \mathrm{El}$ análisis de discurso surge durante el siglo XX como causa y efecto de dos hechos clave: i) el cuestionamiento del quehacer y del valor de la verdad del ejercicio científico y ii) la profunda transformación de los medios de comunicación y su incidencia en los fenómenos sociales y políticos. En otras palabras, se cuestiona la razón objetiva y universal que utiliza el método positivista, entendiéndola ahora como "otra forma social de reproducir y perpetuar relaciones de poder” (Pardo 2007:15). En el desarrollo de los estudios del discurso es posible reconocer la influencia de diversos enfoques, teorías y autores. Para nuestro trabajo tomaremos los aportes del Análisis Crítico del Discurso (ACD) donde el énfasis está puesto en la perspectiva crítica que evidencia las ideologías y las relaciones de poder en una sociedad (Norman Fairclough; Ruth Wodak; Teun van Dijk, entre otros).

${ }^{10}$ Diario electrónico: www.elmostrador.cl. Sección: País. Período de revisión: 11 de noviembre al 17 de diciembre de 2010. Notas identificadas: 55 notas. La alta cantidad de notas de "El Mostrador" en relación a los otros dos medios se justifica en la 
actualización permanente que este medio realiza durante la jornada, incluyendo noticias breves de reciente aparición que los otros medios sintetizan en la edición del día siguiente.

${ }^{11}$ Edición digital: www.latercera.cl. Sección: País /Negocios. Período de revisión: 11 de noviembre al 17 de diciembre de 2010. Notas identificadas: 18 notas.

${ }^{12}$ Edición digital: www.emol.cl. Sección: Nacional. Período de revisión: 01 de noviembre al 19 de diciembre de 2010. Notas identificadas: 19 notas.

${ }^{13}$ Notas sobre la cobertura de los medios de prensa. En el diario El Mostrador se visibilizan los actores parlamentarios, dando cuenta de una cobertura más extensa de los discursos públicos de los involucrados, el foco está en las demandas y temas del conflicto. Las declaraciones seleccionadas son más extensas. En las intervenciones de los actores del conflicto seleccionadas por La Tercera se centran en destacar los temas “paros y "marchas" en el discurso. El foco de la información es destacar los efectos del paro de los servicios públicos en la ciudadanía, el estilo discursivo se caracteriza por el uso de la dramatización, destacando como temas claves los efectos de los paros y marchas en la ciudadanía. En el diario Emol (El Mercurio on line) la cobertura se centra en destacar el uso de cifras para reflejar los niveles de adhesión o bien de unidad interna de los empleados públicos en relación a las demandas, se incorporan mayor número de declaraciones de los gremios del sector con incorporación de representantes provenientes de regiones y Santiago respectivamente. Además incorpora declaraciones del Ministro del Interior, exaltando el tema "paros ilegales" en la cobertura de la noticia; esta última denominación refleja el debate público de carácter histórico que prohíbe el derecho a huelga de los funcionarios del sector público que está en la legislación chilena. Hay un mayor nivel de aparición de los representantes de los gremios apelando a los efectos de los paros en la atención de la ciudadanía en la lógica de la prestación de servicios sociales y se genera destematización y fragmentación del discurso. En la selección de los temas de la noticia, se destaca el tema orden público como efecto de las paralizaciones y marchas de los funcionarios públicos en el desarrollo del conflicto y se evidencia la incorporación de declaraciones del Ministro del Interior, respondiendo desde la lógica del "orden público”, siendo el diario El Mostrador el único que no adiciona el tema en la cobertura de la noticia.

${ }^{14}$ Carta abierta del candidato Sebastián Piñera a los funcionarios del sector público, 2009.

${ }^{15}$ Pliego de Negociación Colectiva Sectorial 2010. ANEF, 2010. Otras demandas que conformaban el petitorio fueron la garantía de estabilidad laboral; un bono especial al retiro para contrarrestar el daño previsional a los empleados públicos; un aumento de la asignación por concepto de modernización; la modificación en la forma de establecer la asignación de zona; la necesidad de incrementar los niveles de participación de los trabajadores, entre otras.

${ }^{16}$ Las reparticiones que experimentaron dichos ajustes, según la prensa escrita, fueron los Ministerios de Planificación, Educación, Bienes Nacionales, Vivienda, Transporte, Salud, servicios públicos dependientes y Gobernaciones, Intendencias y Municipalidades a nivel nacional. Se estima que durante el primer semestre se realizaron más de 3.000 desvinculaciones entre personal a contrata y a honorarios, mientras que durante el segundo semestre la cifra habría alcanzado las 7.000 desvinculaciones. 
${ }^{17}$ Durante el proceso legislativo chileno, el Presidente de la República dispone, entre otros poderes formales, del recurso para establecer los "tiempos legislativos" para la discusión y votación de los proyectos de ley a través de la fijación de "urgencias", consagradas constitucionalmente. Ellas son de tres tipos: urgencia simples (30 días); suma urgencia (10 días), y discusión inmediata (3 días).

${ }^{18}$ Se consideran aquellos actores que se vinculen en tres o más oportunidades con el proceso de conflicto.

${ }^{19}$ Se excluye a Carlos Larraín, por no pertenecer a ninguno de los tres sectores identificados (en ese momento ejercía como Concejal de Las Condes y Presidente de RN).

${ }^{20}$ Se evidencia el uso de la personalización del discurso centrando la crítica en la figura del Presidente de la República (Gingras 1998).

${ }^{21}$ En este tema se identifican rituales de recordación apelando a las acciones realizadas en el ejercicio del gobierno de los 20 años de la Concertación (énfasis en el rol de los Ministros de Hacienda) y consolidación del modelo económico neoliberal. 


\section{Bibliografía}

Avimael, Cristo (2011), “Las Redes de Políticas Públicas: presumiendo su cualidad explicativa y reconociendo las relaciones de poder a su interior”. Documento de Trabajo, Facultad Latinoamericana de Ciencias Sociales, México.

Avritzer, Leonardo (2001), “Democracia deliberativa. La recuperación del concepto de deliberación pública en la teoría democrática contemporánea”, Revista Metapolítica $\mathrm{N}^{\circ}$ 5, pp. 50-65.

Camargo, Ricardo (2008), “El carácter traumático del consenso en torno al “Modelo Chileno”: una investigación sobre la elite política democrática post-Pinochet”, Nuevo Mundo Mundos Nuevos [En línea], Coloquios, pp. $1-14$.

Coser, Lewis (1961), Las funciones del Conflicto Social, Fondo de Cultura Económica, México.

Coppedge, Michael (1994), “Instituciones y gobernabilidad democrática en América Latina”, Revista Síntesis N²2, pp. 61-88.

Dahrendorf, Ralf (1966), Sociedad y libertad: hacia un análisis sociológico de la actualidad, Tecnos, España.

Dobry, Michel (1998), Sociología de las crisis políticas, Siglo XXI Editores, España.

Foucault, Michel (1970), El orden del discurso, Fábula Tusquets, Barcelona.

Freund, Julien (1995), Sociología del Conflicto, Servicio de Publicaciones EME, España.

Galtung Johan (1973), Theories of conflict. Definitions, dimensions, negations, formations. Versión electrónica disponible en: http:// www.transcend.org/files/Galtung_Book_Theories_Of_Conflict_single.pdf (revisado 10.07.2011).

Garcés, Mario (2004), "Los Movimientos Sociales Populares en el Siglo XX. Balance y Perspectivas”. Revista Política N 43, INAP, Universidad de Chile, pp.13-33.

Garretón, Manuel Antonio (1991), “La redemocratización política en Chile”, Transición, Inauguración y Evolución. Revista Estudios Públicos, No. 42, pp.101-133.

Gingras, Anne-Marie (1998), "El impacto de las comunicaciones en las prácticas políticas”; en Gauthier, Gilles, Gosselin, André y Mouchon, Jean 
(comps.), Comunicación y Política, Gedisa, España.

Godoy, Óscar (1999), “La transición chilena a la democracia: pactada”, Estudios Públicos N74, pp.79-106.

Habermas, Jurgen (1999), Teoría de la Acción Comunicativa, Taurus Humanidades, Madrid.

Hajer, Maarten (2005), “Coalitions, Practices, and Meaning in Environmental Politics: from Acid Rain to BSE”. En: D. Howarth \& J. Torfing (eds.), Discourse Theory in European Politics, Palgrave Macmillan, pp. 297-315.

Huntington, Samuel (1968), Political Order and Changing Societies, Yale University Press, Estados Unidos.

Instituto de Ciencias Alejandro Lipschutz, ICAL (2011), Programa Legislativo "Reajuste Salarial”, Santiago.

Landowski, Eric (1993), La sociedad figurada. Ensayos de socio semiótica, Universidad Autónoma de Puebla y Fondo de Cultura Económica, México.

Mainwaring, Scott y Scully Timothy (1997), "La institucionalización de los sistemas de partidos en América Latina”, Revista América Latina Hoy, agosto, año/vol 16, Universidad de Salamanca, pp. 91-108.

North, Douglas (1995), Instituciones, cambio institucional y desempeño económico, Segunda Edición, Fondo de Cultura Económica, México.

Olavarría, Mauricio (ed.) (2010), ¿Cómo se formulan las políticas públicas en Chile? Tomo I. La modernización de la Gestión Pública, Editorial Universitaria, Santiago.

Organización Internacional del Trabajo, OIT (1999), Memoria del Director General: Trabajo Decente, $87^{\circ}$ Reunión de la Conferencia Internacional del Trabajo, Ginebra.

Pardo, Neyla (2007), Cómo hacer análisis crítico del discurso. Una perspectiva latinoamericana, Frasis, Santiago.

Parsons, Talcott (1968), La estructura de la Acción Social, Guadarrama, Madrid.

Sabatier, Paul A. (ed.) (2007), Teorías del proceso de las políticas públicas, Westview Press -Proyecto de Modernización del Estado, Jefatura de Gabinete de Ministros, Buenos Aires.

Schumpeter, Joseph (1952), Socialismo, capitalismo y democracia, Ediciones Aguilar, Madrid. 
Searle, John (1969), Speech acts: An essay in the philosophy of language. Cambridge,University Press.

Siavelis, Peter (2009), “Enclaves de la transición y democracia chilena”, Revista de Ciencia Política, número 29, pp.3-21.

Simmel, Georg (2010), El conflicto. Sociología del antagonismo, Sequitur, Madrid.

Teichman, Judith (2009), “Competing Visions of Democracy and Development in the Era of Neoliberalism in Mexico and Chile”, International Political Science Review, Vol. 30, N 1, pp. 67-87.

Van Dijk, Teun (2005), Estructuras y Funciones del Discurso. Decimotercera edición, Siglo Veintiuno Editores, México.

Idem (2005), "Política, ideología y discurso”, en Quorum Académico, Vol. 2, N², Universidad de Zulia. pp. 15-47.

Wodak, Ruth \& Meyer, Michael. (2003), Métodos de análisis crítico del discurso, Gedisa, Barcelona, España.

Wodak, Ruth (2000) "Rise of racism - an Austrian or a European phenomenon?”, Discourse \& Society, 11(1): 5-6.

Wodak, Ruth. y Van Dijk, T. (eds.) (2000), Racism at the top. Parliamentary Discourses on Ethnic Issues in Six European States, Drava Verlag, Klagenfurt.

Recibido: 09.04.2013

Aceptado: 15.11.2013 